\title{
LAJU INFILTRASI PADA PENGGUNAAN LAHAN DI IUPHKM HUTAN LINDUNG TANDUNG BILLA KELURAHAN BATTANG
}

\section{(Infiltration rate on land use in IUPHKm in Tandung Billa Protection Forest, Battang Village)}

\author{
Asrul $^{1}$, Yumna $^{2}$, Srida Mitra Ayu ${ }^{3}$ \\ Program Studi Kehutanan Fakultas Kehutanan Universitas Andi Djemma Palopo \\ asrul.sylvais@gmail.com)
}

\begin{abstract}
The low infiltration rate causes most rainwater that falls to the ground to become surface runoff, and only a tiny portion of the water can enter the soil as groundwater storage. The infiltration in the Tandung Billa IUPHKm location includes forest land, shrubs, and mixed gardens; the management carried out by the community at the Tandung Billa IUPHkm location is the cultivation of agricultural/plantation crops under tree stands in hilly or slightly sloping areas. Land use in the Tandung Billa Community Forest Utilization Business Permit (IUPHKm) consists of forest land, shrubs, and mixed gardens, each land use affects soil and land conditions which in turn will affect the infiltration rate of the land. Therefore it is necessary to know how the infiltration rate in forest land use, mixed garden shrubs. Measurement of the infiltration rate was carried out by taking soil samples for physical properties, and soil moisture content in three different land uses, namely forest, shrub, and mixed garden land use; the measurement was carried out using a doublering infiltrometer. The results showed that the infiltration rate on forest land was classified as medium-fast. Namely $=83 \mathrm{~mm} /$ hour, with clay texture, then the infiltration rate in shrubland was classified as moderate, namely $=.62 \mathrm{~mm} /$ hour, with clay soil texture and clay. The mixed garden land/agroforestry infiltration rate is classified as mild, namely $=53 \mathrm{~mm} /$ hour with a dusty clay texture.
\end{abstract}

Keywords: Land Use, Soil Texture, Water Content.

\begin{abstract}
ABSTRAK
Laju infiltrasi yang rendahmenyebabkan sebagian besar air hujan yang jatuh ke tanah akan menjadi aliran permukaan dan hanya sebagian kecil air yang dapat masuk ke dalam tanah sebagai simpanan air tanah. Infiltrasi yang ada di lokasi IUPHKm Tandung Billa meliputi penggunaan lahan hutan, semak belukar dan kebun campuran, pengelolaan yang dilakukan masyarakat pada lokasi IUPHkm Tandung Billa adalah budidaya tanaman Pertanian/perkebunan di bawah tegakan pohon pada daerah perbukitan atau yang landai Penggunaan lahan di Izin Usaha Pemanfaatan Hutan Kemasyrakatan (IUPHKm) Tandung Billa terdiri dari lahan hutan, semak belukar dan kebun campuran, setiap penggunaan lahan berpengaruh terhadap kondisi tanah dan lahan yang pada akhirnya akan mempengaruhi laju infiltrasi pada lahan tersebut. maka dari itu perlu diketahui bagaimana laju infiltrasi pada penggunaan lahan hutan, semak belukar dan kebun campuran. Pengukuran dilakukan dengan menggunakan double ring infiltrometer.Hasil penelitian menunjukan bahwa laju infiltrasi pada lahan hutan tergolong sedang-cepat yaitu sebesar $=83 \mathrm{~mm} / \mathrm{jam}$, dengan tekstur tanah lempung berliat, laju infiltrasi pada lahan semak tergolong sedang yaitu sebesar $=.62$ $\mathrm{mm} / \mathrm{jam}$, dengan tekstur tanah lempung berliat dan laju infiltrasi pada lahan kebun campuran/agroforestry tergolong sedang yaitu sebesar $=53 \mathrm{~mm} / \mathrm{jam}$ dengan tekstur tanah liat berdebu.
\end{abstract}

Kata Kunci : Penggunaan Lahan, Tekstur Tanah, kadar air. 


\section{PENDAHULUAN}

Kawasan hutan mempunyai peran yang sangat penting dalam siklus hidrologi karena fungsi hutan salah satunya adalah sebagai penjaga tata air atau Daerah Aliran Sungai (DAS). Hutan sebagai regulator air, artinya memasok air pada musim tertentu dan mengeluarkannya pada musim kering. Oleh karena itu, keseimbangan air dalam hutan harus terus terjaga karena pemanfaatannya yang yang terus meningkat. Namun, ketersediaan air dalam tanah akan berubah jika siklus hidrologi daerah berhutan terganggu (Andayani W.S 2009)

Infiltrasi adalah suatu kegiatan masuknya air kedalam tanah secara vertikal melalui permukaan tanah, kondisi ini sangat dipengaruhi oleh sifat pori tanah, kadar air, tekstur, struktur, kepadatan tanah, kandungan bahan organik tanah, dan keadaan vegetasi permukaan tanah tersebut. Pengaruh vegetasi terhadap erosi adalah menghalangi air hujan agar tidak jatuh langsung dipermukaan tanah, menghambat aliran permukaan dan memperbanyak air infiltrasi, serta memperkuat penyerapan air ke dalam tanah oleh transpirasi melalui vegetasi.Makin rapat vegetasi makin efektif terjadinya pencegahan erosi.

Pada Penggunaan lahan yang berbeda akan dijumpai jenis vegetasi dan tingkat pengolahan lahan yang berbeda (Sun et all. 2018). Dimana kedua hal tersebut juga akan menyebabkan terjadinya laju infiltrasi yang berbeda. Laju infiltrasi yang tinggi tidak hanya meningkatkan jumlah air yang tersimpan dalam tanah untuk pertumbuhan tanaman, tetapi juga mengurangi banjir dan erosi yang diaktifkan oleh run off (Hakim, 1986).

Laju infiltrasi yang rendah, menyebabkan sebagian besar air hujan yang jatuh ke tanah akan menjadi aliran permukaan dan hanya sebagian kecil air yang dapat masuk ke dalam tanah sebagai simpanan air tanah (Lestar, et all., 2019). Hal ini menyebabkan terjadi banjir dimusim hujan, meningkatnya erosi, dan kekeringan di musim kemarau. Akan tetapi, laju infiltrasi yang terlalu tinggi juga akan menyebabkan penurunan produktivitas tanah akibat adanya pencucian unsur hara yang tinggi. Oleh karena itu, peresapan air kedalam tanah melalui infiltrasi menjadi suatu komponen yang penting untuk dikaji. Nilai laju infiltrasi ini dapat menjadi informasi yang penting sebagai acuan dalam pengelolaan air, manajemen tanah dan penggunaan laha yang lebuh sesuai.

Pengelolaan yang dilakukan masyarakat pada lokasi IUPHkm Tandung Billa adalah budidaya tanaman Pertanian/perkebunan di bawah tegakan pohon pada daerah perbukitan atau yang agak landai. Perbedaan yang mencolok adalah jenis tanaman/vegetasi yang berbeda, kerapatan vegetasi dan teknik pengelolaan tanah.

Berdasarkan hasil observasi lapangan di lokasi IUPHKm Tandung billa Kelurahan Battang bahwa masyarakat memanfaatkannya sebagai lahan bercocok tanam seperti jahe, cengkeh, serai, kunyit, lengkuas, vanili, kakao dan lain-lain. Oleh sebab itu infiltrasi pada lahan yang dikelola oleh masyarakat dengan lahan yang belum dikelola akan berbeda, untuk itu dilakukan penelitian dengan judul laju infiltrasi pada beberapa penggunaan lahan. Karakteristik lahan dan penggunaan lahan yang berbeda dengan daerah lainnya, diprediksi akan menunjukkan laju infiltrasi yang berbeda pula (de Almeida et all., 2018; Saputra et all., 2021).

Penggunaan lahan di Izin Usaha Pemanfaatan Hutan Kemasyrakatan (IUPHKm) Tandung Billa terdiri dari lahan hutan, semak belukar dan kebun campuran, setiap penggunaan lahan berpengaruh terhadap kondisi tanah dan lahan yang pada akhirnya akan mempengaruhi laju infiltrasi pada lahan tersebut. maka dari itu perlu diketahui bagaimana laju infiltrasi pada penggunaan lahan hutan, semak belukar dan kebun campuran pada loksi Izin Pemanfaatan 
Hutan Kemasyarakatan (IUPHkm) Tandung Billa.

Tujuan penelitian ini untuk mengetahui laju infiltasi pada beberapa penggunaan lahan di lokasi Izin Usaha Pemanfaatan Hutan Kemasyarakatan (IUPHkm) Tandung Billa.

\section{METODE PENELITIAN}

Penelitian ini dilaksanakan selama \pm 3 bulan dimulai bulan September sampai November 2018 di Izin Usaha Pemanfaatan Hutan Kemasyarakatan (IUPHKm) Tandung billa, Kelurahan Battang Kecamatan Wara Barat Kota Palopo.

Alat yang digunakan adalah kamera, laptop, GPS, dauble ring infiltrometer, stopwatch, air, ember, cangkul, meteran, mistar, serta alat tulis menulis.

Jenis data yang akan dikumpulkan dalam penelitian terdiri atas 2 yaitu : data primer dan data sekunder.

Pengukuran laju infiltrasi yang dilakukan dengan pengambilan sampel tanah untuk sifat fisik yaitu tesktur dan kadar air tanah dilakukan pada tiga penggunaan lahan yang berbeda yaitu penggunaan lahan hutan, semak belukar dan kebun campuran, pengukuran dilakukan dengan menggunakan double ring infiltrometer pada masingmasing lahan. Pengukuran laju infiltrasi sebanyak tiga kali pada masing-masing plot dengan lama waktu pengukuran 120 menit setiap plot dengan selang waktu tertentu.

\section{Analisis Data}

Laju infiltrasi konstan ditetapkan dengan perhitungan perbandingan penurunan muka air yang konstan dengan waktu pengukuran (Susanawati, 2019):

Keterangan

$$
\mathbf{f t}=\Delta \mathbf{h} / \Delta \mathbf{t}
$$

$$
\begin{aligned}
& \mathrm{ft}: \text { Laju Infiltrasi (mm/jam) } \\
& \Delta \mathrm{h}: \text { Penurunan Muka Air } \\
& (\mathrm{mm}) \\
& \Delta \mathrm{f}: \text { Waktu (jam) }
\end{aligned}
$$

\section{Kadar air}

Perhitungan kadar air tanah dilakukan di Laboratorium Tanah Universitas Hasanuddin dengan metode Gravimetry (Abdurachman et all., 2005):

$\mathrm{KA}=\frac{\mathrm{BB}-\mathrm{BK}}{\mathrm{BK}} \boldsymbol{X} 100 \%$

Keterangan

$$
\begin{aligned}
& \text { KA : Kadar air tanah } \\
& \text { BB : Berat basah tanah } \\
& \text { BK : Berat kering tanah }
\end{aligned}
$$

\section{Tekstur tanah}

Adapun penentuan tekstur tanah dilakukan dilakukan di Laboratorium Tanah Universitas Hasanuddin dengan prosedur sebagai berikut :

a) Menyiapkan 25 gram sampel tanah dan memasukkannya kedalam botol plastik.

b) Menambahkan $10 \mathrm{ml}$ larutan Calgon $5 \%$ dan $100 \mathrm{ml}$ aquadest.

c) Memindahkan hasil kocokan kedalam wadah dan mengocok lagi dengan mixer selama 10 menit.

d) Menyaring hasil kocokan dan menampung suspense dalam wadah, begitu pula dengan pasir yang tersisa pada penyaring.

e) Memindah kansus pensi kedalam gelas ukur $500 \mathrm{ml}$.

f) Mengocok suspensis elama 8 detik dan mengukur dengan hydrometer (H1) dan thermometer (T1) setelah 40 detik.

g) Melanjutkan pada pengamatan setelah 8 jam (H2\&T2).

h) Memanaskan pasir yang telahditampung hingga kering dan menimbang berat pasir.

i) Menghitung perbandingan antara debu, pasir dan liat.

Untuk perhitungan tekstur tanah dilakukan dengan rumus (Hadjowigeno, 2002), sebagai berikut : 


$$
\begin{aligned}
& \mathrm{A}=(\text { beratDebu }+ \text { Liat })=\mathrm{H} 1+\frac{0,3 \times(\mathrm{T} 1-19,8)-0,5}{2} \\
& \mathrm{~B}=(\text { beratLiat }) \quad=\mathrm{H} 2+0,3 \times(\mathrm{T} 2-19,8)-0,5 \\
& 2 \\
& \mathrm{C}=(\text { beratpasir }) \quad=\text { pasir } \\
& \% \text { Liat }=\frac{B}{A+C} \times 100 \% \\
& \% \text { Debu }=\frac{A-B}{A+c} \times 100 \% \\
& \% \text { Pasir }=\frac{c}{A+C} \times 100 \%
\end{aligned}
$$

Keterangan

$$
\begin{array}{ll}
\mathrm{H} & \text { : Hidrometer } \\
\mathrm{T} & \text { : Termometer }
\end{array}
$$

Laju infiltrasi yang diperoleh diklasifikasikan berdasarkan Kohnke (1959) seperti yang disajikan pada Tabel 1 .

Tabel 1. Klasifikasi Laju Infiltrasi Tanah

\begin{tabular}{lc}
\hline \multicolumn{1}{c}{ Kelas } & $\begin{array}{c}\text { Laju Infiltrasi Konstan } \\
(\mathrm{mm} / \mathrm{jam})\end{array}$ \\
\hline Sangat Lambat & $<1$ \\
Lambat & $1-5$ \\
Sedang - Lambat & $5-20$ \\
Sedang & $20-65$ \\
Sedang - Cepat & $65-125$ \\
Cepat & $125-250$ \\
Sangat Cepat & $>250$ \\
\hline Sumber : (Kohnke, 1959) &
\end{tabular}

\section{Regresi}

Hubungan antara laju infiltrasi dengan beberapa sifat fisik tanah melalui analisis regresi linier dengan metode regresi linier sederhana.

Keterangan :

$$
Y=a+b X
$$

$\mathrm{Y}=$ Laju infiltrasi $(\mathrm{cm} / \mathrm{jam})$

$\mathrm{X}=$ tekstur

$\mathrm{a}=$ Konstanta

$\mathrm{b}=$ Koefisen regresi
Pedoman untuk memberikan interpretasi koefisien determinasi disajikan pada tabel berikut.

Tabel 2. Kriteria Nilai Koefisien Determinasi

\begin{tabular}{cc}
\hline $\begin{array}{c}\text { Interval koefisien } \\
\text { Determinasi }\end{array}$ & Tingkat Korelasi \\
\hline 0 & Tidak ada korelasi \\
$>0-0,25$ & Korelasi sangat lemah \\
$>0,25-0,5$ & Korelasi Cukup \\
$>0,5-0,75$ & Korelasi kuat \\
$>0,75-0,99$ & Korelasi sangat kuat \\
1 & Korelasi sempurna \\
\hline Sumber : (Sarwono, 2009) &
\end{tabular}

\section{HASIL DAN PEMBAHASAN}

Penelitian laju infiltrasi pada beberapa penggunaan lahan yang berbeda yaitu penggunaan lahan hutan, semak belukar dan kebun campuran yang berada di lokasi Izin Usaha Pemanfaatan Hutan Kemasyarakatan (IUPHkm) Tandung billa. Berikut merupakan peta lokasi penelitian pada gambar 2.

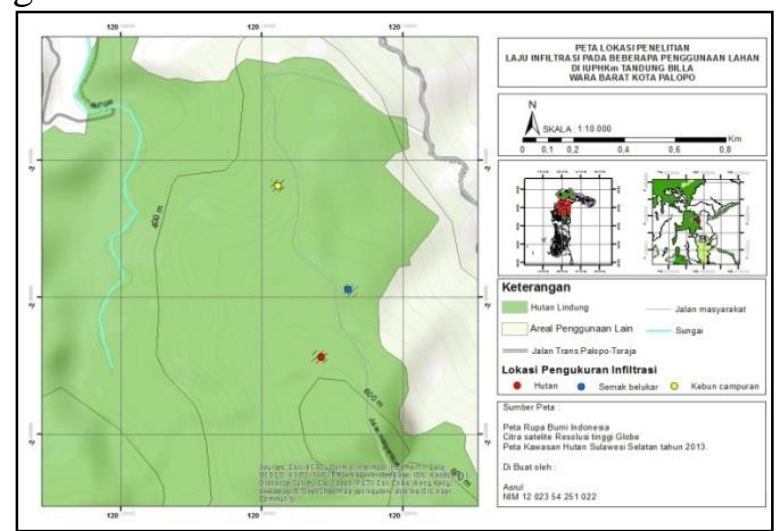

Gambar 2. Peta Lokasi Penelitian Infiltras

\section{Lahan hutan}

Jenis tanaman hutan yang terdapat pada lokasi penelitian antara lain nyato (Palauium sp.) sinangkala, liasa, bakan dan betau (Chalophylium) selain itu terdapat tanaman penutup tanah berupa semak dan rerumputan yang jumlah tidak terlalu banyak. Pada lahan hutan ini tidak dilakukan pengolahan tanah sama sekali oleh masyarakat sehingga sifat-sifat tanahnya tetap terjaga dengan baik. Karena lokasi ini 
Volume 3 Nomor 1 Juli 2021:35-44

merupakan salah satu daerah tanggapan air sehingga masyarakat tidak memanfaatkannya sebagai lokasi bercocok tanam, sedangkan kemiringan lereng pada lahan hutan sebesar $18,3 \%$

\section{Lahan semak belukar}

Lahan semak belukar yang digunakan merupakan lahan yang ditumbuhi rumput liar yang ditumbuhi rerumputan dengan tinggi \pm $30 \mathrm{~cm}$. Tidak adanya tajuk tinggi yang berada di lahan tersebut mengakibatkan suhu udara dan tanah cukup tinggi karena terpapar cahaya matahari langsung. Semak belukar dapat dikatakan sebagai penutup tanah yang dapat berfungsi untuk menjaga kesuburan tanah secara alami. Tumbuhan liar yang berada di semak belukar didominasi oleh rerumputan dan tumbuhan liar seperti alangalang (Imperata cylindrica), kemiringan lerengsebesar $17,8 \%$

\section{Lahan kebun campuran}

Kebun campuran merupakan penggunaan lahan yang terdiri dari beberapa jenis tanaman yang di tanam menggunakan budidaya intensif, Penanaman umumnya dilakukan dengan pengolahan tanah dibawah tegakan pohon, Tanaman yang terdapat di lokasi penelitian adalah Sengon (Albizia chinensis), pete (Parkia speciosa), lengkuas (Alpinia galanga), cacao (Theobroma cacao) serei (cymbopogon citratus), Jahe (Zingiber officinale), dan kunyit (Curcuma longa). Sedangkan kemiringan lereng pada lahan kebun campuran sebesar 17,5\%.

\section{Tekstur tanah}

Tekstur tanah atau perbandingan pasir, debu dan liat pada lokasi penelitian dapat dilihat pada tabel 3 .

Tabel 3. Tekstur tanah

\begin{tabular}{|cccccc}
\hline \multirow{2}{*}{ No } & $\begin{array}{c}\text { Penggunaan } \\
\text { Lahan }\end{array}$ & \multicolumn{3}{c}{$\begin{array}{c}\text { Komposisi Partikel } \\
\text { Tanah (\%) }\end{array}$} & \multirow{2}{*}{$\begin{array}{c}\text { Kelas } \\
\text { Tekstur }\end{array}$} \\
\cline { 3 - 5 } & Pasir & Debu & Liat & \\
\hline 1 & Hutan & 21 & 40 & 39 & Lempung \\
2 & Semak & 23 & 42 & 35 & Lempung
\end{tabular}

\begin{tabular}{llllll} 
belukar & & & & berliat \\
Kebun & \multirow{2}{*}{$\begin{array}{l}\text { Kebun } \\
\text { Campuran }\end{array}$} & 17 & 41 & 42 & $\begin{array}{l}\text { Liat } \\
\text { berdebu }\end{array}$ \\
\hline
\end{tabular}

Sumber : :(Laboratorium Universitas Hasanuddin, 2018)

Tabel 2 di atas menunjukan bahwa kebun campuran dengan tekstur tanah liat berdebu memiliki infiltrasi yang lebih lambat dibandingkan penggunaan lahan hutan dan semak belukar yang bertekstur lempung berliat.Hal ini dsebabkan komposisi partikel tanah pada kebun campuran didominasi oleh liat dan memiliki kandungan pasir lebih sedikit. Tanah yang memiliki kandungan liat lebih banyak dibandingkan pasir akan memiliki kemampuan meloloskan air ke dalam tanah lebih lambat dibandingkan tanah dengan kandungan pasir yang lebih banyak .pasir memiliki pori makro yang lebih banyak sehingga lebih muda dilalui oleh air. Perbedaan komposisi antara pasir, debu dan liat akan menyebabkan laju infiltrasi yang berbeda. Hal ini sejalan dengan pandapat Sarief (1985), Faktor sifat fisik tanah yang dominan mempengaruhi infiltrasi yaitu tekstur tanah. Jika pada tekstur lempung berliat laju infiltrasi lebih rendah dibanding pada tekstur lempung liat berpasir, ini menunjukkan bahwa semakin kasar tekstur tanah maka semakin cepat air masuk kedalam tanah dan sebaliknya semakin halus tekstur tanah maka semakin lambat air masuk kedalam tanah.

\section{Kadar air tanah}

Hasil pengukuran kadar air tanah pada tiga penggunaan lahan yaitu lahan hutan, lahan semak belukar dan lahan kebun campuran, dapat dilihat pada gambar berikut.

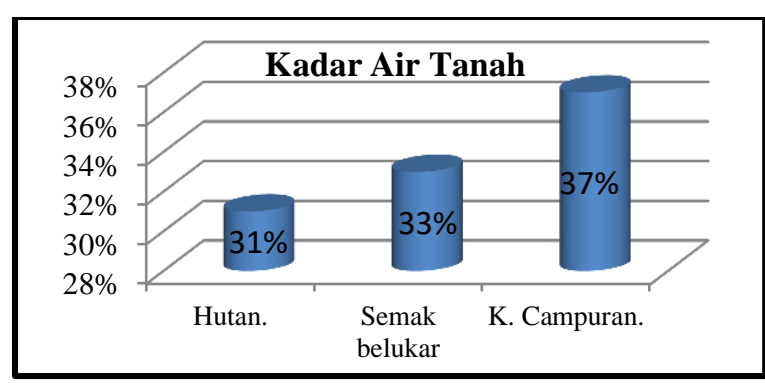

Gambar. 3 Kadar Air Tanah 
Dari gambar 3 di atas terlihat bahwa kadar air pada lahan hutan sebesar $31 \%$, pada lahan semak belukar $33 \%$ dan pada lahan kebun campuran $37 \%$. Perbedaan persentase kadar air masing-masing penggunaan lahan berbeda disebabkan karena tekstur tanah dan kondisi lahan yang berbeda-beda. Lahan kebun campuran memiliki tekstur tanah liat berdebu dengan komposisi liat yang lebih tinggi dibandingkan pasir. Sedangkan pada lahan hutan memiliki tekstur tanah lempung berliat dengan komposisi liat yang lebih sedikit serta komposisi pasir yang lebih banyak. Selain itu vegetasi yang rapat dan perakaran yang banyak sehingga pori makro yang terbentuk besar. Menurut Rachim (2001) pori-pori dalam suatu massa tanah merupakan rongga-rongga diantara partikelpartikel tanah yang dapat berisi air dan udara, maka semakin rendah pori-pori yang dapat diisi oleh udara atau sebaliknya.

\section{Perbandingan Laju Infiltrasi beberapa penggunaan lahan}

Hasil pengukuran laju infiltrasi pada tiga penggunaan lahan disajikan pada gambar berikut.

Tabel 4. Laju Infiltrasi pada beberapa Penggunaan Lahan

\begin{tabular}{clcl}
\hline No & Lokasi & $\begin{array}{l}\text { Laju Infiltrasi } \\
(\mathbf{m m} / \mathbf{J a m})\end{array}$ & Kriteria \\
\hline 1 & Hutan & 83 & $\begin{array}{l}\text { Sedang - } \\
\text { Cepat }\end{array}$ \\
2 & $\begin{array}{l}\text { Semak } \\
\text { Belukar } \\
\text { kebun } \\
\text { Campuran }\end{array}$ & 62 & Sedang \\
3 & 53 & Sedang \\
\hline
\end{tabular}

Sumber : Data primer setelah diolah, 2018.

Pada tabel 4 terlihat bahwa Laju infiltrasi pada lahan hutan sebesar $=83$ $\mathrm{mm} / \mathrm{jam}$, lahan semak belukar $=.62 \mathrm{~mm} / \mathrm{jam}$ dan pada lahan kebun campuran sebesar $=53$ mm/jam. Menurut kriteria kohnke (1968), laju infiltrasi pada hutan tergolong infiltrasi Sedang-cepat dan sedang untuk lahan semak belukar dan kebun campuran termasuk kriteria sedang.

Menurut Sofyan (2006) tingginya laju infiltrasi minimum pada lahan hutan disebabkan oleh tinggi pori makro menyebabkan kemampuan tanah meloloskan air semakin besar, sehingga laju infiltrasi tanahnya juga semakin besar. Selain itu, vegetasi hutan juga berpengaruh besar terhadap proses terjadinya infiltrasi tanah. Akar tanaman selain membantu menyerap air yang masuk kedalam tanah karena meningkatnya evapotranspirasi, juga membantu pembentukan saluran air ke dalam tanah berupa bekas akar yang membusuk.

Sedangkan menurut Sofyan 2006), kandungan liat yang tinggi cenderung meningkatkan jumlah pori mikro yang dapat mengurangi kemampuan tanah untuk meloloskan air, namun pada lahan hutan terjadi hal yang sebaliknya karena liat bersama bahan organik membentuk agregat/granul yang dapat meningkatkan jumlah pori makro dan memperlancar aerasi, sehingga meningkatkan besarnya laju infiltrasi pada lahan hutan.

Sedangkan pada penggunaan lahan semak belukar memiliki laju infiltrasi lebih rendah dari penggunaan lahan hutan karena hanya terdapat satu jenis vegetasi yaitu Rumput, laju infiltrasi pada lahan terbuka dikategorikan sebagai laju yang sedang.Menurut Andara (2008), besarnya laju infiltrasi pada lahan hutan dipengaruhi oleh kerapatan tajuk yang bervariasi dan vegetasi tanaman bawah dibandingkan dengan lahan terbuka yang tidak memiliki tajuk pohon.

Sedangkan pada lahan kebun campuran memiliki laju infiltrasi lebih rendah dari pada lahan semak belukar karena adanya pengelolaan tanah, pengaruh jangka pendek dan aktivitas manusia di areal tersebut. Menurut Buckman and Brady (1969) dalam Sofyan M (2006) pengelolahan tanah yang dilakukan secara terus-menerus akan mempercepat komposisi bahan organik dan menghancurkan bongkah-bongkah/agregatagregat yang telah terbentuk, ketika terjadi 
Volume 3 Nomor 1 Juli 2021:35-44

hujan maka agregat-agregat tanah hancur dan kepadatan tanah meningkat, sehingga kemampuan tanah melolskan air semakin rendah.

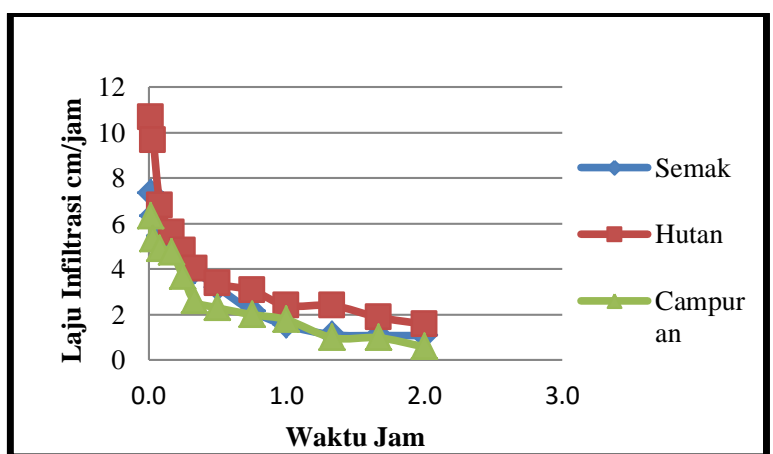

Gambar 4.Laju Infiltrasi pada beberapa Penggunaan lahan.

Gambar diatas menunjukan bahwa infiltrasi berjalan cepat pada menit pertama sampai menit 60, kemudian berjalan lambat hingga akhirnya konstan pada menit selanjutnya hingga menit ke 120 . Sedangkan kapasitas infiltrasi tertinggi pada menit pertama berada pada lokasi lahan hutan dengan penurunan air sebesar $10,7 \mathrm{~cm} / \mathrm{jam}$, kemudian kapasitas infiltrasi terendah berada pada kebun campuran dengan penurunan air di menit pertama sebesar $6,3 \mathrm{~cm} / \mathrm{jam}$.

\section{Hubungan Laju Infiltrasi pada penggunaan lahan dengan tekstur tanah (komposisi debu liat dan pasir).}

Hasil analisis regresi linier sederhana menunjukan bahwa tekstur tanah dalam hal ini fraksi debu tidak mempunyai pengaruh yang sangat nyata terhadap laju infiltrasi dengan nilai signifikan $0,522>0,05$, namun memiliki korelasi yang kuat dengan koefisien determinasi $\left(\mathrm{R}^{2}\right)$ sebesar 46,5\% dengan persamaan regresi $\mathrm{Y}=462,5+-9,75 \mathrm{x}$ disajikan pada (Gambar 6.).

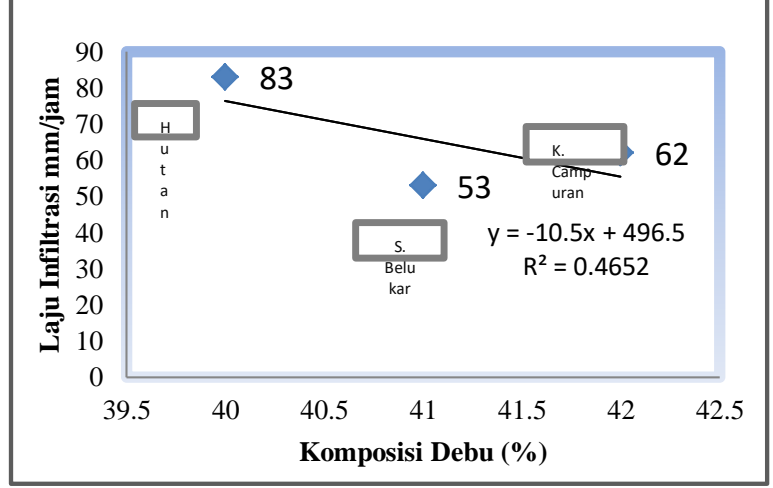

Gambar 6.Hubungan Laju Infiltrasi dengan Komposisi Debu.

Pada Gambar 6 terlihat bahwa pada lahan kebun campuran memiliki komposisi debu yang lebih besar dibandingan dengan semak belukar dan hutan, hal ini menunjukan bahwa semakin besar komposisi debu pada tekstur tanah maka semakin kecil laju infiltrasi pada lahan tersebut. Menurut Soniari (2016), Debu sulit membentuk agregat yang mantap dan berukuran relative kecil sehingga mudah dihanyutkan oleh aliran permukaan. Tanah-tanah yang banyak mengandung debu paling mudah tererosi karena debu sangat mudah dihanyutkan oleh air dan cepat penurunan kapasitas infiltrasinya,.

Sedangkan untuk fraksi liat menunjukan bahwa tidak mempunyai pengaruh yang sangat nyata terhadap laju infiltrasi dengan tingkat korelasi sangat lemah dengan nilai $0,21>0,05$, persamaan regresi $\mathrm{Y}=102,054+-0,932 \mathrm{x}$ dengan koefisien determinasi $\left(\mathrm{R}^{2}\right)=0,05$.

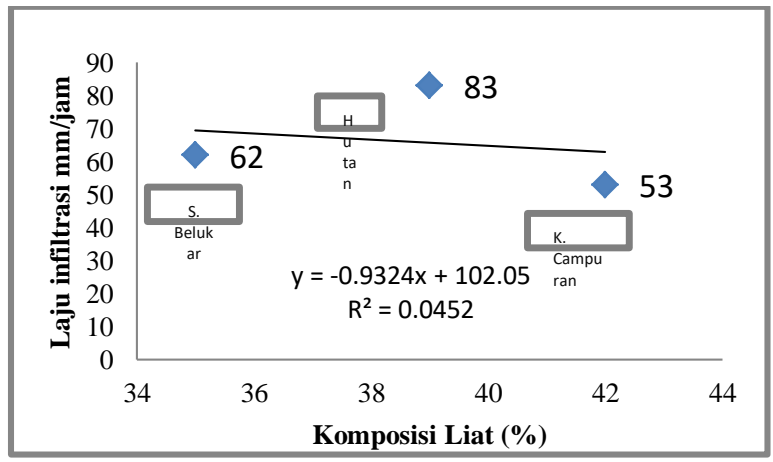

Gambar7.Hubungan Laju Infiltrasi dengan Komposisi Liat 
Pada Gambar 7 terlihat bahwa komposisi liat tertinggi terdapat pada lahan kebun campuran dan terendah pada lahan semak belukar, hal ini menunjukan semakin besar fraksi liat dalam suatu tekstur maka laju infiltrasi pada lahan tersebut semakin kecil. Menurut Hardjowigeno (2003), tanahtanah dengan kandungan liat yang lebih tinggi mempunyai luas permukaan yang lebih besar sehingga kemampuan menahan air tinggi.

Sedangkan untuk fraksi pasir menunjukan bahwa tidak mempunyai pengaruh yang sangat nyata terhadap laju infiltrasi, namun memiliki nilai korelasi yang kuat dengan nilai signifikan $0,69>0,05$, dengan persamaan regresi yang terbentuk $\mathrm{Y}=18,071+-2,357 \mathrm{x}$ dengan koefisien determinasi $\left(\mathrm{R}^{2}\right)=0,22$.

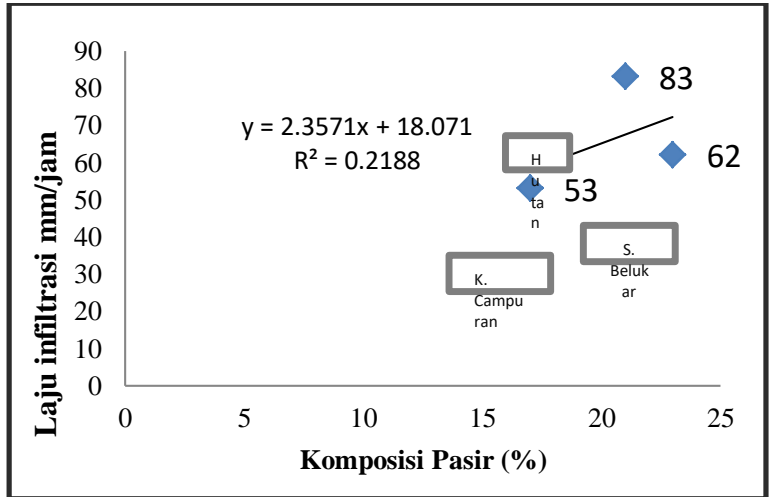

Gambar8. Hubungan laju infiltrasi terhadap komposisi pasir

Pada Gambar 8. Menunjukan bahwa komposisi pasir tertinggi terdapat pada lahan semak belukar dan terendah pada kebun campuran, perbedaan komposisi pasir pada penggunaan lahan tersebut sangat berpengaruh terhadap laju infiltrasi, hal disebabkan karena semakin besar komposi pasir suatu lahan maka semakin cepat laju infiltrasi pada lahan tersebut. Menurut Prasetyo (2011), tanah pasir memiliki tekstur yang kasar. Terdapat ruang pori-pori yang besar diantara butiran-butirannya sehingga kondisi tanah ini menjadi struktur yang lepas dan gembur. Dengan kondisi yang seperti itu menjadikan tanah pasir ini memiliki kemampuan yang rendah untuk dapat mengikat air.

\section{Hubungan infiltrasi dengan kadar air tanah}

Hasil analisis regresi linier sederhana menunjukan bahwa kadar air tanah tidak memiliki pengaruh nyata dengan nilai signifikan $0,378>0,05$. Namun memilki nilai korelasi yang sangat kuat dengan persamaan regresi $\mathrm{Y}=-4.6071 \mathrm{x}+221.11$ kemudian koefisien determinasi $\left(\mathrm{R}^{2}\right)$ sebesar 0,84 .

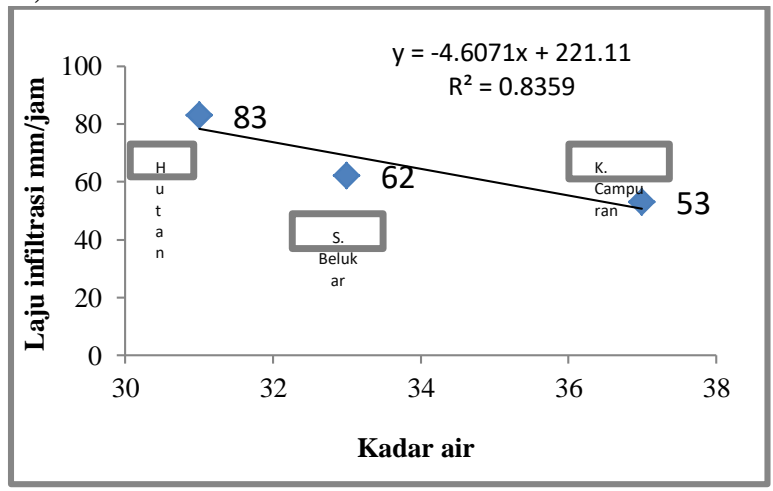

Gambar 9.Hubungan Laju Infiltrasi dengan Kadar air tanah

Pada Gambar 9. Menunjukan pada lahan kebun campuran memiliki kadar air yang tinggi dan kadar air terendah pada lahan hutan, hal ini sebebkan karena semakin tinggi kadar air pada suatu lahan maka semakin rendah laju infiltrasi. Menurut Dong, J., \& Ochsner, T. E. (2018), semakin tinggi kandungan liat atau semakin halus fraksi tanah maka semakin tinggi kadar air tanah. Sebaliknya semakin tinggi fraksi kasar (pasir sangat kasar, pasir kasar pasir sedang) maka semakin rendah kadar air tanah.

\section{KESIMPULAN}

Berdasarkan hasil analisis dan pembahasan hasil penelitian yang berjudul llaju infiltrasi pada beberapa penggunaan lahan dapat disimpulkan bahwa laju infiltrasi pada lahan hutan tergolong sedang-cepat yaitu sebesar $=83 \mathrm{~mm} / \mathrm{jam}$, dengan tekstur tanah lempung berliat, kemudian laju infiltrasi pada lahan semak tergolong sedang 
yaitu sebesar $=.62 \mathrm{~mm} / \mathrm{jam}$, dengan tekstur tanah lempung berliat dan laju infiltrasi pada lahan kebun campuran/agroforestry tergolong sedang yaitu sebesar $=53 \mathrm{~mm} / \mathrm{jam}$ dengan tekstur tanah liat berdebu. Laju infiltrasi pada beberapa penggunaan lahan sangat dipengaruhi oleh tekstur tanah dan kadar air tanah.

\section{DAFTAR PUSTAKA}

Abdurachman, A., Haryati, U., \& Juarsah, I. 2005. Penetapan Kadar Air Tanah Dengan Metode Gravimetrik. Kata pengantar, 131.

Andara, A. 2018. Laju Infiltrasi pada Tegakan Mahoni dan lahan Terbuka di Universitas Hasanuddin.Skripsi.

Fakultas Kehutanan, Unhas.

Andayani W.S 2009. Laju infiltrasi tanah pada tegakan jati di BKPH subah KPH Kendal unit I Jawa Tengah, Skripsi. Depertemen Silvikultur Fakultas Kehutanan IPB.

De Almeida, W. S., Panachuki, E., de Oliveira, P. T. S., da Silva Menezes, R., Sobrinho, T. A., \& de Carvalho, D. F. 2018. Effect of soil tillage and vegetal cover on soil water infiltration. Soil and Tillage Research, 175, 130138.

Dong, J., \& Ochsner, T. E. 2018. Soil texture often exerts a stronger influence than precipitation on mesoscale soil moisture patterns. Water Resources Research, 54(3), 2199-2211.

Hardjowigeno, 2003. Ilmu Tanah. Akademika Pressindo. Jakarta
Hakim. 1986. Dasar-dasar ilmu tanah, penerbit PT raja Grafindo Persada. Jakarta

Isyari, A. 2005. Pendugaan laju infiltrasi pada beberapa penggunaan lahan di DAS Ciliwung bagian hulu, Skripsi. Departemen Geofisika dan Meteorologi, Fakultas MIPa, IPB.

Lestari, E., Makarim, C. A., \& Pranoto, W. A. 2019. Zero runoff concept application in reducing water surface volume. In IOP Conference Series: Materials Science and Engineering (Vol. 508, No. 1 , p. 012019. IOP Publishing.

Mahendra, F. 2009. Sistem agroforestry dan Aplikasinya. Graha Ilmu. Yogyakarta.Hal 39, 115.

Saputra, N. E., Wibowo, C., \& Lisnawati, Y. 2021. Analysis of soil physical properties and infiltration rates for various landuses at Gunung Dahu Research Forest, Bogor District, West Java Province. In IOP Conference Series: Earth and Environmental Science (Vol. 713, No. 1, p. 012034). IOP Publishing.

Sarief, E.F. 1985. Konservasi Tanah dan Air. Pustaka Buana. Bandung.

Seyhan E. 1990. Dasar-dasar Hidrologi. Yogyakarta (ID): Gadjah Mada University Press

Sofyan, M. 2006. Pengaruh berbagai penggunaan lahan terhadap laju infiltrasi tanah, Skripsi.ProgramStudi Ilmu Tanah, fakultas Pertanian IPB. Bogor.

Sun, D., Yang, H., Guan, D., Yang, M., Wu, J., Yuan, F., ... \& Zhang, Y. 2018. The effects of land use change on soil infiltration 
capacity in China: A metaanalysis. Science of the Total Environment, 626, 13941401.

Susanawati, L. D., Rahadi, B., \& Tauhid, Y. 2019. Penentuan Laju Infiltrasi Menggunakan Pengukuran Double Ring Infiltrometer dan Perhitungan Model Horton pada Kebun Jeruk Keprok 55 (Citrus Reticulata) Di Desa Selorejo, Kabupaten
Malang. Jurnal Sumberdaya Alam dan Lingkungan, 5(2), 28-34.

Yanrilla, R. 2001. Laju Infiltrasi pada berbagai jenis penutupan lahan hutan di RPH Tenjowaringin, $\quad \mathrm{BKPH}$ Singaparna, $\quad \mathrm{KPH}$ Tasikmalaya, perum perhutani Unit III Jawa Barat.Skripsi.Jurusan Manajemen hutan. Fakultas Kehutanan. IPB. 